\title{
SABERES PEDAGÓGICOS
}

Revista do Curso de Graduaçào de Pedagogia - Unesc

ISSN 2526.4559

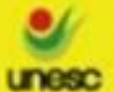

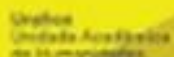

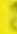

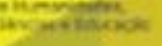

O CONCEITO DE FRAÇÃO POSICIONAL E AS OPERAÇÕES DE ADIÇÃO E

SUBTRAÇÃO NO MODO DAVYDOVIANO DE ORGANIZAÇÃO DO ENSINO

\section{THE CONCEPT OF POSITIONAL FRACTION AND ADDITION AND \\ SUBTRACTION OPERATIONS IN THE DAVYDOVIANO MODE OF TEACHING \\ ORGANIZATION}

\section{Ademir Damazio 1 \\ Lucas da Silva Fernandes ${ }^{2}$}

\begin{abstract}
RESUMO: A presente pesquisa traz como centralidade o estudo do conceito de frações posicionais e suas insidências nas operações de adição e de subtração. Seu objetivo é estudar o modo davydoviano de organização de ensino para os referidos conceitos matemáticos, que traz/tem como pressuposto o desenvolvimento do pensamento teórico. Com isto, surge o problema: Como é organizado o ensino do conceito de frações posicionais na proposta davydoviana? Trata-se de um estudo qualitativo de natureza bibliográfica. Para tanto, adota como base empírica de análise as tarefas do livro didático russo do $6^{\circ}$ ano (GORBOV, et al., 2016), articulada com a fundamentação na Teoria Histórico-Cultural e do Ensino Desenvolvimental. No processo de análise, levou-se em consideração o movimento conceitual em três níveis: o sistema de dígito, as frações posicionais propriamente ditas e operações (adição e subtração). Em cada um deles, a referência foi tarefas que os caracterizassem, além de explicitar a possibilidade de colocar os estudantes em situação investigativa, pois cada uma delas cria necessidade para suas resoluções e identificação de relações conceituais. $O$ estudo apresenta evidências de que, no modo davydoviano de organização do ensino, o conceito de fração posicional, bem como das operações de adição e subtração, é abordado a aprtir da base genética: a relação entre grandezas com representação em diversas bases. Portanto, os números com vírgula são estudados não só em sua representação decimal, mas nos diferentes sistemas numéricos.
\end{abstract}

PALAVRAS-CHAVE: Organização do Ensino, Fração Posicional, Sistemas Numéricos, Grandeza.

\footnotetext{
${ }^{1}$ Professor do Programa de Pós Graduação em Educação. Docente da Unesc. add@ unesc.net

2 Graduando em Licenciatura Plena em Matemática na Universidade do Extremo Sul Catarinense/Unesc.lucas2000fernandes@hotmail.com
} 


\section{SABERES PEDAGÓGICOS}

Revista do Curso de Graduaçào de Pedagogia - Unesc

ISSN 2526-4559

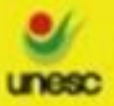

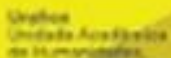

ABSTRACT: The main focus of this research is the study of the concept of positional fractions and their influence on addition and subtraction operations. It has as objective to study a Davydovian way of organizing teaching for the aforementioned mathematical concepts, which presupposes the development of theoretical thinking. With this, the problem arises: How is the teaching of the concept of positional fractions organized in the davydovian proposal? This is a qualitative bibliographic study. Therefore, it adopts as an empirical basis for analysis the tasks of the 6th grade Russian textbook (GORBOV, et al., 2016), articulated with the foundations of Historical-Cultural Theory and Developmental Teaching. In the analysis process, the conceptual movement in three levels was taken into account: the digit system, the positional fractions themselves and operations (addition and subtraction). In each of them, the reference was some tasks that characterized them, in addition to explaining the possibility of placing students in an investigative situation, as each one of them creates a need for their resolutions and identification of conceptual relationships. The study shows that, in the Davydovian mode of teaching organization, the concept of positional fraction, as well as the addition and subtraction operations, brings as genetics the relation between quantities with representation in different bases. Therefore, the numbers with comma, are studied not only in their decimal representation, but in different number systems.

KEYWORDS: Teaching Organization, Positional Fraction, Numerical Systems, Magnitude.

\section{INTRODUÇÃO}

Os números, como são conhecidos hoje, suprem necessidades históricas importantes, por exemplo: a contagem e a medição, que basicamente constituem sua base genérica. As primeiras evidências de contagens surgiram a mais de 50000 anos a. C. e muito se desenvolveu até chegar-se ao que se concebe, na atualidade (EVES, 2004). Isso se justifica pela evolução da realidade humana, o que faz a matemática dos egípcios e babilônicos emergir de necessidades distintas daquelas peculiares aos matemáticos da NASA que fazem cálculos complexos para possibilitar as viagens ao espaço. $\mathrm{Na}$ contemporaneidade, os números, assim como as palavras que compõem um idioma universal, são indispensáveis, para explicar e relacionar-se com o mundo das relações sociais e Universo.

Em meio a esse complexo sistema que envolve os números, uma questão se apresenta: Como organizar o seu ensino que considere o seu desenvolvimento lógico-histórico e, portanto, observe a existência do que veio a originá-lo? Esse questionamento sugere implicitamente a concepção pedagógica com fundamentos na Teoria Histórico-cultural

Saberes Pedagógicos, Criciúma, v. 5, n² 2, maio/agosto 2021.- Curso de Pedagogia- UNESC 
(VIGOTSKI, 2001) e do Ensino Desenvolvimental (DAVÍDOV, 1988) ${ }^{1}$. Nesse sentido, Davídov (1988) propõe argumentos de que a relação genética dos números é estabelecida entre as grandezas de várias espécies entre si, o que explica a obtenção das diferentes singularidades numéricas (positivos, negativos, naturais, racionais, irracionais e reais). É com essa base que o autor e seus colaboradores propõem um modo geral de organização para que os alunos desenvolvam o pensamento teórico em relação à matemática. Um olhar para a literatura que revela a produção de conhecimento, referente ao ensino do conceito de número como proposto pelo grupo de Davídov, vale alguns destaques. Dois deles (ROSA, 2012; SOUZA, 2013) tratam do modo pelo qual a proposição davidoviana organiza o ensino do número inteiro positivo no primeiro ano escolar. Com o mesmo objetivo, Freitas (2016) centra-se no conceito de número fracionário positivo. Assim também, Búrigo (2015) foca na introdução dos números negativos. Observa-se que não há nenhum estudo que trata do conceito de fração decimal. A maior aproximação está na pesquisa de Rosa, Damazio e Silveira (2014) que aborda o número e suas operações em diversas bases.

Por isso, a presente pesquisa é delimitada pelo seguinte problema: Como é organizado o ensino do conceito de fração posicional na proposta davydoviana? Para orientar a investigação desse problema, outras questões foram levantadas: Em que ano escolar ocorre a maior evidência para o conceito de fração posicional na referida proposta? O que caracteriza a organização do ensino do conceito em foco, no ano escolar em que ele é enfatizado? Em que sistema conceitual a fração posicional se apresenta? Por decorrência, objetivo geral é: Analisar o modo pelo qual é organizado o ensino do conceito de números decimais, na proposta davydoviana. Mais especificamente, estabelecemos outros objetivos atinentes às questões auxiliares: 1) Identificar de modo analítico o ano escolar que ocorre a maior evidência para o conceito de número decimal na referida proposta; 2) Apontar as características da organização do ensino do conceito em foco, no ano escolar em que ele é enfatizado; 3) Analisar o sistema conceitual em que a fração decimal se apresenta.

\footnotetext{
${ }^{1}$ As grafias Davídov, Davidov, Davýdov e Davydov conservam o modo que elas são adotadas na própria obras citadas. Quando nos dirigimos ao autor, usamos Davýdov e, na adjetivação de sua proposição de organização de ensino, adotamos davydoviano.

Saberes Pedagógicos, Criciúma, v. 5, n², maio/agosto 2021.- Curso de Pedagogia- UNESC
} 
Metodologicamente, o estudo adota uma abordagem qualitativa, cujo fundamento é de que exite "uma relação dinâmica entre o mundo real e o sujeito, uma interdependência viva entre o sujeito e o objeto, um vínculo indissociável entre o mundo objetivo e a subjetividade do sujeito" (CHIZZOTTI, 1991, p.79). Essa inter-conexão entre a tríade sujeito/pesquisador-objeto-mundo se objetivou, na pesquisa, ora em processo de exposição, ao traduzir a preocupação e atenção para com: a organização do ensino de conceito matemático (número fracionário representado por vírgula); uma concepção teórica com entendimento adverso aos sistemas de ensino tradicionais (DAVÍDOV, 1988); e uma concepção do conceito matemático em foco que extrapola a simples ideia de fração decimal; e recorre à análise que articulou esss três centralidades com a base empírica, as tarefas particulares com teor conceitual do sistema conceitual matemático em foco.

Esta base empírica de análise é algumas tarefas particulares ${ }^{2}$, extraídas do livro didático, em língua russa, do $6^{\circ}$ ano: Горбов, et al. (2016). Os pressupostos perseguidos, nessa obra, são de que o modo adotado para a organização do ensino possibilta, aos alunos, se envolverem em um processo investigativo, com vista à explicitação da essência dos conceitos científicos. Por consequência, promove o desenvolvimento do pensamento conceitual teórico (DAVÍDOV, 1988). As tarefas particulares analisadas foram escolhidas a partir dos seguintes critérios: 1) expressassem ideias do conceito de fração, cuja representação adota vírgula; 2) apresentassem algumas características diferentes em relação às anteriores. $\mathrm{O}$ processo de análise teve como centralidade os seguintes aspectos: o elemento conceitual presente na tarefa; a resolução da tarefa com base no modo geral de ação, proposto na organização do ensino; o elemento conceitual diferenciador de uma tarefa para outra. Por decorrência, ocorreu a possibilidade de identificar os componentes da relação essencial do conceito e explicitá-los em um modelo. A preocupação também se voltou para a inter-relação com a base teórica, mais especificamente, no que diz respeito à organização do ensino proposta por Davídov (1988), cujos pressupostos constituirão a sessão seguinte.

\footnotetext{
${ }^{2}$ Tarefas particulares se constituem em um dos componentes da estrutura do modo davidoviano de Organização de Ensino, que será apresentada na próxima seção.

Saberes Pedagógicos, Criciúma, v. 5, nº 2, maio/agosto 2021.- Curso de Pedagogia- UNESC
} 


\section{BASES DA ORGANIZAÇÃO DE ENSINO PROPOSTAS POR DAVÍDOV}

Trazer um conceito para ser analisado no âmbito de uma organização de ensino considerada uma das mais diferentes, atual e promissora para o desenvolvimento humano (LIBÂNEO; FREITAS, 2013) - requer o entendimento e a explicitação dos seus fudamentos. Tal necessidade é reveladora da compreensão de que existem modos e modos de organização da atividade pedagógica que, mesmo na mais discreta diferença entre um e outro, reccorem a uma concepção teórica, muitas vezes, não conhecida pelos professores.

Por isso, a necessária explicitação do lugar teórico em que se insere o presente estudo, qual seja, a interface entre as teorias: Histórico-Cultural, da Atividade de Estudo e do Ensino Desenvolvimental. Todas elas têm como matriz o Materialismo Histórico e Dialético, cujos principais fundamentos são:

(1) a história da filosofia, que aparece como uma sucessão de doutrinas filosóficas contraditórias, dissimula um processo em que se enfrentam o princípio idealista e o princípio materialista; (2) o ser determina a consciência e não inversamente; (3) toda a matéria é essencialmente dialética, e o contrário da dialética é a metafísica, que entende a matéria como estática e anistórica; (4) a dialética é o estudo da contradição na essência mesma das coisas (ALVES, 2010).

Esses fundamentos foram traduzidos por Vigostki (1896-1934) para a Psicologia que, atualmente, é conhecida como Histórico-Cultural. Eles têm como objeto a atividade, referência de estudo sobre a formação das funções tipicamente humanas. Os seus principais pressupostos, pertinentes ao objeto de estudo do presente artigo, dizem respeito à concepção de desenvolvimento humano, formação de conceito, bem como a relação entre aprendizagem e desenvolvimento.

Vigotski (2001) adota como princípio a sociabilidade do homem, isto é, ele nasce e se desenvolve, tanto biológica quanto cognitivamente, em grupo social com suas específicas ideologias e culturas, que se constituem em determinates produzidos historicamente. Por consequência, no contexto escolar e da atividade pedagógica, o processo de elaboração conceitual dos estudantes requesita por um modo geral de organização de ensino que prima

Saberes Pedagógicos, Criciúma, v. 5, n², maio/agosto 2021.- Curso de Pedagogia- UNESC 
por interações sociais - professor e escolares - mediadas por sígnos, palavras, um conceito em nível científico. Nesse sentido, Freitas (2016, p. 238) traduz o papel atribuído à escola, em conformidade com preceitos da Teoria Histórico-Cultural:

a escola deve assumir identidade emancipatória e ter como objetivo promover o desenvolvimento dos alunos por meio da formação integral, proporcionada pela apropriação da herança cultural histórica, constituída da produção não material e material, originada no processo criativo social humano em resposta às necessidades sociais, cujos resultados se encontram encarnados nos conhecimentos teóricos e práticos e nas práticas sociais, nas várias áreas de conhecimento englobando as ciências, as técnicas, as artes, os valores morais, as relações humanas.

A orientação de Vigotski (2001) é que o ensino escolar e a educação proporcionem as condições para que os estudantes, de modo gradual, se apropriem dos conceitos científicos. Contudo, o que o autor entende por conceito científico?

[...] é reflexo objetivo das coisas em seus aspectos essenciais e diversos; se forma como resultado da elaboração racional das representações, como resultado do descobrimento dos nexos e as relações do objeto com os outros. Inclui em si, portanto, um grande proceso de pensamento e conhecimento que, diría-se, está concentrado nele (VYGOTSKI, 1996, p. 81, tradução nossa).

Em outras palavras, trata-se de um sistema de relações estabelecidas, historicamente, que chegou ao nível de abstração com base em leis, princípios, teorias e propriedades peculiares. Portanto, é fruto de um processo de análise e síntese e se expressa em uma linguagem, que o torna independente do contexto. A apropriação, em contexto escolar, requer uma atenção intencional e voluntária, por parte dos estudantes (VYGOTSKI, 1996).

Sua compreensão, com caráter de pressuposto, é de que as apropriações não se referem aos conceitos em si, mas das suas significações, que se apresentam por consequências de determinadas condições histórico-culturais, ocorridas ao longo do seu desenvolvimento. Desse modo, um conceito não se forma e nem é apropriado de modo isolado, pois está sempre atrelado a outros, constituindo um sistema conceitual. Para Vygotski (1996, p. 71):

É muito estreito e interessante o vínculo entre os diversos conceitos. A recíproca Saberes Pedagógicos, Criciúma, v. 5, n², maio/agosto 2021.- Curso de Pedagogia- UNESC 
inter-relação e transferência dos conceitos, que é um reflexo da recíproca transferência e vinculação dos fenômenos da realidade, trazem por consequiência que cada conceito surge relacionado com todos os restantes e, uma vez formado, vem a determinar, por assim dizer, seu lugar no sistema de conceitos anteriormente.

Por extensão, todo conceito científico sempre se apresenta de forma mediatizada por outros conceitos, em um sistema hierárquico interno de inter-relações. Os conceitos cientiíficos, em nível teórico, são entendidos como aquilo que mais desenvolvido a humanidade produziu no processo histórico. A apropriação desses conceitos é o que proporciona as condições para o desenvolvimento, pelos estudantes, das suas máximas capacidades, isto é, o pensamento conceitual teórico. Este tipo de pensamento, conforme Davidov e Markova (2019) se constitue em um dos fundamentos para a formação psicológica mais ampla do homem, isto é, a sua consciência teórica. Ele surge e se manifesta quando a criança - ao estudar um ou outro objeto - apresenta necessidades tais como: de estabelecer um modo generalizado de orientação referente a uma área do conhecimento; de elaborar um modo generalizado de resolução de um conjunto de problemas. O pensamento teórico está vinculado à generalização teórica, que se diferencia totalmente da genereralização empírica. Esta última, segundo Davidov (2019, p. 172, grifos no texto original),

[...] está relacionada com a distinção, mediante a comparação das propriedades gerais e aparentemente iguais, de alguma variedade dos objetos com a seguinte orientação da pessoa para essas propriedades. A generalização teórica do conteúdo envolve a análise das condições de origem de algum sistema de objetos mediante sua transformação real ou psíquica. Essa análise destaca a relação geneticamente inicial ou universal, que constitui a base das manifestações particulares do sistema. Nesse caso, os termos conteúdo e teórico não podem ser identificados com os de abstrato $e$ verbal-discursivo.

Foi com vista ao desenvolvimento do pensamento conceitual científico teórico, nos estudantes, que Davidov liderou por muitas décadas uma equipe de pesquisadores, que produziu, com base experimental, os fundamentos, simultâneos, tanto da Teoria da Atividade de Estudo e como do Ensino Desenvolvimental (LIBÂNEO, FREITAS, 2013).

Davídov (1988) admite a compreensão de Leontiev que o homem se desenvolve e, Saberes Pedagógicos, Criciúma, v. 5, n², maio/agosto 2021.- Curso de Pedagogia- UNESC 
em diferentes estágios, há uma atividade principal que os caracterizam, indicadora da possibilidade concreta de ele estar em determinado lugar social. Essas atividades principais destacadas pelo autor são: o jogo, na idade pré-escolar; o estudo, período escolar; e o trabalho na fase adulta. Sua preocupação e atenção foram com a teorização da atividade de estudo e desenvolvimento dela pelos estudantes. Davídov (1988) concebe, assim como Leontiev, a atividade de estudo como tendo a mesma estrutura de todas as atividades humanas: 1) elementos essenciais, constituidos pelas necessidades e os motivos, os objetivos, as condições; elementos decorrentes que dizem respeito aos meios de seu alcance, que são as ações e operações. No último artigo, divulgado depois de sua morte, Davydov (1999) faz reflexões referentes a novos componentes da estrutura da atividade - com indicação de algumas discordâncias de certas relações estabelecidas por Leontiev - quais sejam: emoções, desejos, vontade com inter-relações com as necessidades, motivos e finalidade.

Nos experimentos formativos, base empírica de suas pesquisas sobre a teorização da Atividade de Estudo e da organização do Ensino Desenvolvimental, Davýdov e o grupo de pesquisadores, estabelecem a seguinte organização: tarefas gerais de estudo, ações de estudo e tarefas particulares. Na especificidade do estudo da Matemática, Davídov (1988, p. 188) indica como primeira tarefa de estudo "obtenção e o emprego do número como meio especial de comparação das grandezas". Isso significa que uma tarefa de estudo está vinculada ao objeto da Matemática e, por extensão, de seu ensino. Por exemplo, as frações representadas por vírgula se apresentam na relação entre grandezas e se constituem em uma sigularidade do número real, por decorrência de que, no processo de medição, a unidade básica de medida não cabe, uma quantidade inteira naquela que está sendo medida (FREITAS, 2016).

Para Davidov (2019, p. 172), a formulação, ao aluno, de "uma tarefa de estudo, significa colocá-lo em uma situação que requer uma orientação para um modo generalizado de ação, desde o ponto de vista do conteúdo de sua solução em todas as suas variantes particulares e concretas possíveis das condições".

Para cada tarefa de estudo, o modo de organização proposta e seguida em suas pesquisad experimentais (posteriormente, tranformado em um dos sistemas de ensino adotado na Rússia e outros países) é desenvolvida por seis ações de estudo: 1) transformação dos Saberes Pedagógicos, Criciúma, v. 5, n², maio/agosto 2021.- Curso de Pedagogia- UNESC 
dados da tarefa para revelar a relação universal, geral, do objeto em processo de estudo; 2) modelação da relação universal na unidade, que ocorre nas formas objetal, gráfica e literal; 3) transformação do modelo revelador da relação universal proporcionada pelo estudo da suas propriedades em forma pura; 4) elaboração de um e resolução de um sistema de tarefas particulares que preservam um procedimento geral; 5) controle da realização das ações anteriores; 6) avaliação reveladora das apropriações, com base no procedimento geral, resultante da solução da tarefa de estudo.

Para a efetivação de cada uma dessas seis ações, os estudantes são colocados diante de um conjunto de tarefas particulares, a serem por eles desenvolvidadas, cuja caracterísitica essencial é colocá-los em movimento investigativo em busca das soluções dos problemas e questionamentos propostos. Segundo Davídov (1988), diferença entre as tarefas de estudos e as tarefas particulares está em que as primeiras apresentam as condições necessárias para que os estudantes se apropriem do procedimento geral de ação, além de desenvolverem, novos conceitos. No caso das frações representadas por vírgula, os estudantes assimilam o modo geral de ação pertinente à relação (medição) entre duas grandezas de mesma espécie, quantificada por um determinado valor.

Por sua vez, as tarefas particualres são elaboradas de modo tal que propiciam que esse modo geral de ação levam ao domínio dos procedimentos adotados para a solução de situações particulares. Essas tarefas permitem, por exemplo, que os estudantes adotem o mesmo modo de ação geral para se defrontar com medidas cujos valores não são inteiros e que requerem por representações mais complexas, como é o caso com números com vírgula em várias bases. Portanto, ao analisar tais procedimentos, os estudantes identificam aquilo que é geral, predominante, na complexidade do sistema. De acordo com Davídov (1988), no pensamento, ocorre o movimento dialético do trânsito do geral para o particular.

É com base nessas orientações teóricas que a próxima seção tratará de analisar tarefas particulares do livro didático do sexto ano escolar (ГОРБОВ, et al., 2016), pertinentes ao sistema de ensino Elkonin-Davidov, com centralidade para aquelas relacionadas ao conceito matemático objeto do presente estudo. 


\section{SABERES PEDAGÓGICOS}

Revista do Curso de Graduaçào de Pedagogia - Unesc

ISSN 2526.4559

\section{O DESENVOLVIMENTO DOS NÚMEROS COM VÍRGULA NO MODO DE ORGANIZAÇÃO DO ENSINO}

De início, vale esclarecer a razão pela qual adotamos a denominação de "números com vírgula". Isso ocorreu ao verificarmos que, nos livros didáticos do modo davidoviano de organização de ensino, não existia a nomenclatura ou um título "números decimais". O nosso entendimento, que justifica tal ausência, é de que a fração, seja qual for ela, é desenvolvida em todas as bases numéricas. Portanto, difere do que ocorre no ensino brasileiro, em que o foco é exclusivo na base dez, que nos induziu - de início - para buscarmos a fração ou número decimal, como objeto de estudo. Por decorrência da investigação, entendemos que o melhor termo é: fração posicional com vírgula, como será explicado adiante. Desse modo, o referido conceito se apresenta no âmbito conceitual do sistema de numeração, o que nos leva a tratá-lo na subseção a seguir.

\subsection{Sistemas de numeração e tipos de contagem}

Partindo do pressuposto de que, no modo de organização do ensino davydoviano, o número decimal se constitui em apenas uma especificidade no âmbito da fração com notação por vírgula (posicional), consideramos importante, previamente situar o leitor no que diz respeito aos sistemas de numeração e às respectivas contagens. Para tanto, importa antecepar que, nos livros didáticos que objetivam a proposição davydoviana, é evidente as tarefas citarem as seguintes características: ação de medição dos diversos tipos de grandeza, sua representação na reta numérica e elaboração de modelos reveladores da relação universal do conceito. Do processo de medição, são geradas necessidades para demonstrar os seus resultados, em termos de diferentes tipos de números e de distintas bases (o que requer outros modos de agrupamentos). Nesse âmbito, os números são expressões da relação entre uma grandeza de referência e a unidade adotada para medí-la. Isso significa que "o número 1 é o primeiro passo no processo de colocação consecutivas das medidas" (DAVIDOV, 2008, p. 64-65). É essa a ideia necessária para a construção da reta numérica, a fim de representar os valores, do menor para o maior, da esquerda para direita ou vice-versa. Isso ocorre no

Saberes Pedagógicos, Criciúma, v. 5, n², maio/agosto 2021.- Curso de Pedagogia- UNESC 
primeiro ano e se amplia aos fracionários (quarto ano) e aos negativos (quinto ano). Porém, em todo esse período, as tarefas induzem ou proprocionam a aquisição de noções dessa complexificação numérica, uma vez que, ao ser concebido como emergente da relação entre grandezas, potencializa a ideia mais ampla de número real.

Figura 1 - Reta numérica em processo de construção

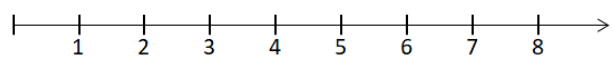

Fonte: Elaboração nossa com base nas tarefas de (GORBOV, et al. 2016)

Dentre outras considerações e expressões da reta numérica anterior (figura 1), chamamos atenção para que não passe despercebida a ausência do número zero. Observa-se que a representação se inicia pelo número um (1), cujo significado é se constituir em unidade. O mesmo acontece com cada elemento da figura, cada qual é implicador da quantidade de unidades que ocupa na reta. $\mathrm{Ou}$, pelos axiomas de Peano, ocupam uma posição imediatamente superior em uma unidade do seu antecessor e inferior em uma unidade do seu sucessor. Tratase de significações produzidas historicamente, tanto por consequência de necessidades humanas, como de desenvolvimento conceitual produzido por matemáticos (ALEKSANDROV, et al. 1991). Outra significação da reta é o seu sentido indicado pela seta. Por exemplo, na figura 1, indica o sentido positivo e o teor aditivo de um número em relação ao anterior. Também, em sua subjacência, contempla a noção inicial de infinitude dos números naturais. Da mesma forma, a seta na extremidade contrária apresenta o teor subtrativo e o sentido contrário (negativo). Por extensão, se explicará a ausência do zero que será suprida por necessidade criada por subtrações sucessivas de uma unidade. Por exemplo, 8 $-1=7 ; 7-1=6 ; 6-1=5 ; 5-1=4 ; 4-1=3 ; 3-1=2 ; 2-1=1 ; 1-1=?$. Isso, segundo Rosa (2012), concede duas significações matemáticas importantes: 1) o zero (0) assume um significado de número, em vez de uma representação do nada, como normalmente é tratado nos anos iniciais da escolaridade; 2) a emergência de necessidade de números negativos que, na reta, se posicionarão à sua esquerda. Desse modo, o zero (0) passa a ser um número de

Saberes Pedagógicos, Criciúma, v. 5, n² 2, maio/agosto 2021.- Curso de Pedagogia- UNESC 
referência. De acordo com Búrigo (2015), o sentido da reta é a manifestação de que o processo de medição superou por incorporação o uso de grandezas escalares por adoção da grandeza vetorial.

Figura 2 - Reta numérica com adicionar seta acréscimo dos números negativos

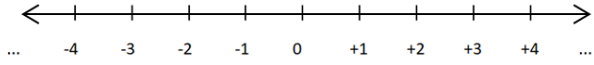

Fonte: Elaboração nossa com base nas tarefas de (GORBOV, et al. 2016)

Vale dizer que as duas representações anteriores tiveram por base sistema decimal, mas no modo de organização de ensino de Davýdov isso ocorre em todas as bases, como veremos mais adiante.

Outra característica essencial dos sistemas numérico é a de posicionamento, o que implica no significado numérico de acordo com a posição ocupada. Isso se tornou um desafio, uma vez que, no contexto do ensino brasileiro, estamos habituados ao estudo em apenas uma base: a dez. Por isso, trataremos dessa especificidade na próxima seção.

Vale antecipar que as primeiras tarefas referentes às frações se apresentam de modo explícito somente no quarto ano escolar. Elas concebem a ideia de que os números, até então conhecidos, não são capazes de medir determinadas grandezas; por isso, a necessidade de números fracionários em diversas bases. Tais necessidades se apresentam paulatinamente nos anos anteriores em que as tarefas criam a possibilidade de subdivisões dos números inteiros. Exemplificamos, no segundo ano escolar, os estudantes desenvolvem o pensamento conceitual de sistema numérico - base dos números fracionários posicionais - que consiste de agrupamentos, cuja representação escrita se localizam, posicionalmente, de acordo com seu significado quantitativo ordinal. Os números estudados têm o posicionamento como uma de suas características. Nesse sentido, indicamos como referência, o número genérico $a b_{m}$, em que $a b$ está na base $m$, sendo $b$ a unidade e $a$ o número de agrupamentos feitos, cada um deles é $m$ vezes maior que $b$.

Depois da apropriação da característica posição, um conjunto de tarefas particulares leva à sua generalização de que, conforme a base numérica em que esse sistema Saberes Pedagógicos, Criciúma, v. 5, n², maio/agosto 2021.- Curso de Pedagogia- UNESC 
está inscrito, dispõe-se, à esquerda, agrupamentos com a constância de $m$ vezes o anterior. Para exempiflicar, recorremos a uma situação de contar certa quantidade de laranjas no sistema quaternário (figura 3). Observa-se que a cada 4 laranjas, simula-se o uso de uma sacola, a cada 4 destas requer uma nova embalagem (maior) que armazene as sacolas menores e, assim, sucessivamente. A figura 3, a seguir, faz a representação da quantidade 27 do sistema decimal, na base quaternária.

Figura 3 - Valor quantitativo de cada agrupamento

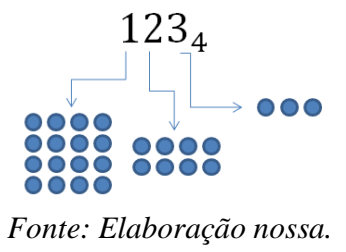

Na figura 3, destaca-se que o primeiro elemento, à direita ou unidade principal (3), representa as três unidades simples, isto é, que não atingiu a quantidade "4" para formar o primeiro agrupamento. Indo da direita para esquerda, encontra-se o número "2", que significa dois agrupamentos com quatro unidades simples - segunda contagem, que forma o primeiro agrupamento. $\mathrm{O}$ algarismo mais à esquerda (1) é o maior agrupamento lido, em relação aos demais. Trata-se de um agrupamento constituído de quatro dos imediatemente anterior (de quatro unidades cada). Na compreensão de sucessivos grupos - cada novo agrupamento formado por outros menores de mesma quantidade de contagem -, importa observar o movimento crescente e decrescente dos valores das ordens representativas deles.

Nessa organização de ensino, as tarefas particulares que imprimem o movimento de apropriação conceitual em cada uma das seis ações de estudo, há um momento que os escolares modelam e transformam (respectivamente, segunda e terceira ações) o modo geral de ação referente ao conceito em processo de estudo/apropriação. Tal generalização, para o conceito de sistema de numeração, é apresentada na figura 4. Nela, a seta indica o movimento crescente, isto é, da primeira à n-ésima ordem.

Saberes Pedagógicos, Criciúma, v. 5, n² 2, maio/agosto 2021.- Curso de Pedagogia- UNESC 
Figura 4 - Valor quantitativo de cada agrupamento

$$
E \stackrel{n}{\longrightarrow} E_{1} \stackrel{n}{\longrightarrow} E_{2} \stackrel{n}{\longrightarrow} E_{3} \stackrel{n}{\longrightarrow} E_{4} \stackrel{n}{\longrightarrow} \ldots
$$

Fonte: (GORBOV, et al. 2016)

"O número $n$ mostra quantas vezes cada próximo algarismo $E$ é maior que o anterior. Ele é chamado de base do sistema numérico" (Горбов, et al. 2016, p. 7). É essencial que se perceba os movimentos na representação numérica ...abn. Os números à esquerda representam maiores quantidades de grupos, cada qual com $n^{x}$ quantidade de unidades. À direita, se tem o contrário e, por consequência, a partir de $n^{0}$ agrupamento chega-se aos números fracionários posicionais com vírgula, que será referência na próxima subseção.

Para ilustrar o exposto, tomamos como referência a tarefa da figura 5.

Figura 5 - Medição da Grandeza B com a unidade E

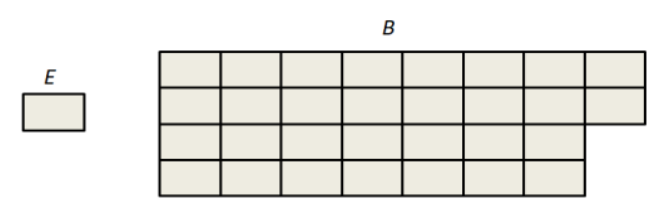

Fonte: Elaboração nossa com base nas tarefas de (GORBOV, et al. 2016)

Ao adotarmos a contagem (agrupamento) na base 4, podemos escrever a medição da grandeza $B$ com a unidade $E$ do seguinte modo: duas vezes a unidade principal ou inicial $(E)$, mais três agrupamentos $\left(E_{1}\right)$ com quatro unidades cada, somados a um agrupamento $\left(E_{2}\right)$ com quatro grupos composto de quatro unidades. Portanto, obtemos: $1 E_{2}+3 E_{1}+2 E$ conforme ilustração da figura 6 .

Saberes Pedagógicos, Criciúma, v. 5, n², maio/agosto 2021.- Curso de Pedagogia- UNESC 


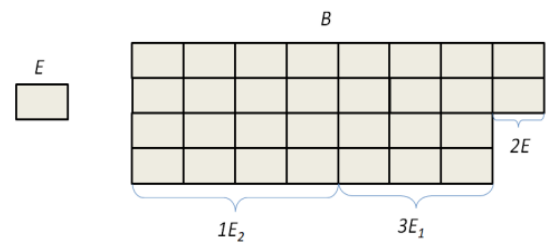

Fonte: Elaboração nossa com base nas tarefas de (GORBOV, et al. 2016)

Isso justifica a característica de posicionamento nos sistemas de numeração, pois, para cada posição em que o número ocupa, as relações de medição apresentam um significado correspondente. Nesse contexto de medição e escritas dos números, conforme o modelo geral dos sistemas de dígitos, é que emerge, no percurso histórico do homem, uma nova necessidade: o número com vírgula, o que será exposto na próxima seção.

\subsection{Ideia do surgimento de números fracionários e sua representação posicional}

No modo davydoviano de organização do ensino, os números fracionários com vírgula trazem como um dos elementos mediadores - para o entendimento do movimento de formação dos grupos - a representação geométrica das situações. A figura 7 explicita esse processo na especificidade do sistema ternário.

Figura 7 - Representação de uma medição com base ternária

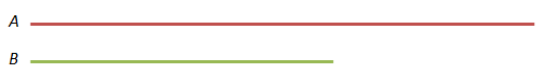

Fonte: Elaboração nossa com base nas tarefas de (GORBOV, et al. 2016)

Ao medir a grandeza A com uma unidade de medida B, considerando que a medida é feita no sistema de base 3, nota-se que cabe uma unidade inteira (1) 3 $_{3}$ e mais uma parte, conforme figura 8 .

Saberes Pedagógicos, Criciúma, v. 5, n², maio/agosto 2021.- Curso de Pedagogia- UNESC 
Figura 8 - Representação de uma medição com base ternária

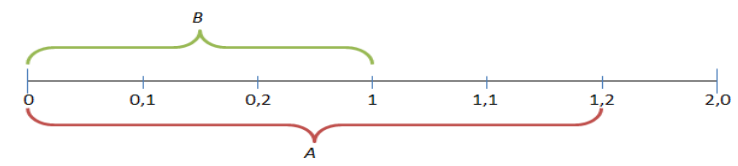

Fonte: Elaboração nossa com base nas tarefas de (GORBOV, et al. 2016)

Então, A representa $(1)_{3} B+(0,2)_{3} B$, ou seja, $(1,2)_{3} B$. É possível a elaboração da percepção, em termos geométricos, da necessidade de subdivisões dos números para que ocorra a medição na forma mais aproximada possível. Por consequência, a "vírgula" aparece nos sistemas numéricos, com o intuito de indicar posicionamento e de evidenciar os números menores que a unidade, com a conservação da mesma base de agrupamento.

Outro destaque da proposição de Davýdov para o ensino de números fracionário com vírgula, é que cada tarefa apresenta novas necessidades. A tarefa 29, a seguir, do livro didático (ГОРБОВ, et al. 2016), é uma indicação de que tem como finalidade o cálculo da área em um sistema numérico de base quaternária (4).

Tarefa 29: Construa a área $\mathrm{D}$, se: $\mathrm{D}=1,2 \mathrm{E}$, sendo $\mathrm{E}$ a figura, a seguir.

Figura 9 - Área de E

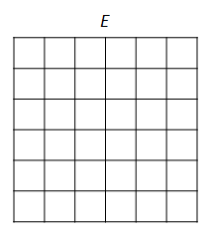

Fonte: Elaboração nossa.

Sabe-se que a área de $\mathrm{D}$ é igual a 1,2 da área de $\mathrm{E}$, ou seja, $\mathrm{D}=1,2 \mathrm{E}$. A resolução pode ocorrer pela reta numérica em um sistema numérico de base quaternária: 
Figura 10 - Recorte da reta numérica inscrita em base quaternária

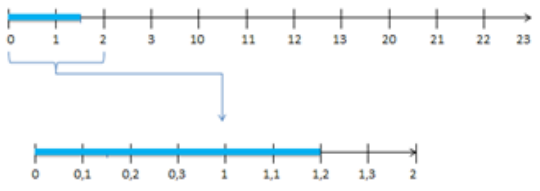

Fonte: Elaboração nossa com base nas tarefas de (GORBOV, et al. 2016)

A operação na reta auxilia a representação da área solicitada $\mathrm{D}=1 \mathrm{E}+0,2 \mathrm{E}$.

Figura 11 - Área de D = E "mais um pouco"

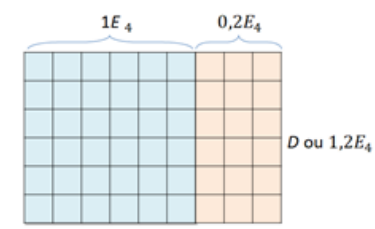

Fonte: Elaboração nossa com base nas tarefas de (GORBOV, et al. 2016)

$\mathrm{A}$ área $\mathrm{E}$ é a unidade de referência para a contrução de $\mathrm{D}$, pois $\mathrm{D}=1,2 \mathrm{E}$ requer acréscimo de 0,2 em E, que representa a metade da área inicial por se tratar da base quatro.

Numa fração posicional com vígula, existe a parte inteira e a fracionada. A parte inteira corresponde à quantidade de grandeza que é esgotada de forma crescente pela unidade principal. Por sua vez, a parte fracionada corresponde ao resto que se apresenta de forma decrescente, conforme representação de Горбов (2016), a seguir.

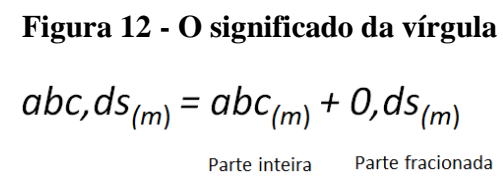

Fonte: Elaboração nossa com base nas tarefas de (GORBOV, et al. 2016)

A inter-relação entre álgebra/aritmética/geometria - peculiariadade do modo davydoviano de organização de ensino de Matemática, confirmada por Rosa (2012) - se evidencia genericamente na presente tarefa. Nela, há tradução de que os significados posicionais de cada número podem ser expressos de forma algébrica. Isso se intensifica com a Saberes Pedagógicos, Criciúma, v. 5, n², maio/agosto 2021.- Curso de Pedagogia- UNESC 
elaboração de uma representação genérica literal que expressa o valor numérico de cada membro, em conformidade com a base numérica em que está inserido:

Figura 13 - O significado do posicionamento dos números em relação à base do sistema numérico

$$
\begin{gathered}
a b c, d s_{(m)} \\
a \cdot m^{2}+b \cdot m^{1}+c \cdot m^{0}+d \cdot m^{-1}+s \cdot m^{-2}
\end{gathered}
$$

Fonte: Elaboração nossa com base nas tarefas de (GORBOV, et al. 2016)

Nessa representação, é possível observar o número $a b c$, de na base numérica $m$. O caso específico de número decimal " 0,001 ” é uma ilustração de uma representação da abstração de um número escrito na base dez: " $0 \cdot 10^{0}+0 \cdot 10^{-1}+0 \cdot 10^{-2}+1 \cdot 10^{-3}$.

$\mathrm{Na}$ amplitude dos números escritos na base dez, as posições que eles ocupam são nomeados: unidade, dezena, centena... Quando menores que uma unidade simples, chamamse números decimais, com as denominações: décimos, centésimos, milésimos, ...

As questões que se apresentam são: Quando os números se encontram em outras bases numéricas, que não a decimal, como pode ser feita a leitura? De que maneira serão pronunciados esses números? Tal leitura é feita pronunciando cada algarismos da esquerda para a direita e no final a indicação da base. Por exemplo, $(13,213)_{4}$, lê-se: um três vírgula dois um três, base quatro.

Vale ressaltar que as tarefas dessa subseção apresentam a necessidade de um novo conjunto numérico, conhecido por racionais não inteiros, também chamado de frações posicionais (ГОРБОВ, et al. 2016) e, aqui, se acresce a nomenclatura 'com vírgula'. Elas são representativas do movimento proposto para o processo de apropriação conceitual pelo modo davydoviano de organização do ensino. Nesse sentido, vale retomar dois, entre outros, pressupostos que o fundamenta. Um deles é a ideia de sistema conceitual (VIGOTSKI, 2001), pois a fração decimal com vírgula, apresenta nexos com os conceitos de: relação entre grandezas, número e seus sitemas posicionais, campos numéricos, para citar alguns. Além disso, contempla a indissociabilidade da relação entre aritmética, álgebra e geometria que, conforme afirmação de Rosa (2012), é uma peculiaridade da proposição davydoviana de

Saberes Pedagógicos, Criciúma, v. 5, n², maio/agosto 2021.- Curso de Pedagogia- UNESC 
organição do ensino. O segundo pressuposto é de que as tarefas particulares não perdem de vista a relação entre grandezas como a base essencial do conceitos matemáticos. Tal relação é o que move o sugimento de necessidade de uma tarefa para com a outra a fim de que os conceitos se apresentem por caminhos teóricos, em vez de empíricos. Por isso, na resolução de cada uma delas ultrapassa a simples observação e recorrência aos órgãos dos sentidos. A análise se efetiva por mediações com outros conceitos matemáticos e modos de ações já apropriados (DAVÍDOV, 1988).

Esses presupostos se constituem em elementos de análise para as operações de adição e subtração com os números, na próxima seção.

\title{
4 ADIÇÃO E SUBTRAÇÃO COM NÚMEROS FRACIONÁRIOS POSICIONAIS COM VÍRGULA
}

Feitas a contextualização da generalização das frações posicionais, focaremos nas operações de adição e subtração. De acordo com Горбов (2016, p. 13):

\begin{abstract}
Adição e subtração das frações posicionais (no mesmo sistema numérico), acontece posicionalmente, da mesma maneira como ocorre com os números inteiros de vários algarismos. A única diferença é que no caso das frações, a equiparação de algarismos de cada casa se dá a partir da vírgula (e não a partir do lado direito do número, como no caso de números inteiros).
\end{abstract}

Para ilustrar a definição anterior, apresentamos a tarefa 39 do livro didático (ГОРБОВ, 2016), qual seja: $(0,223)_{5}+(132,300)_{5}$, cuja resolução desenvolveremos, a seguir.

Nela, optamos em adicionar separadamente cada uma das ordens, a partir da menor, isto é, da direita para esquerda. Observa-se que, por se tratar de um sistema quinário, cada vez que a soma atinge "5", constitui uma nova ordem subsequente. Isso só ocorreu na terceira operação, quando se adiciona a terceira ordem.

Saberes Pedagógicos, Criciúma, v. 5, n², maio/agosto 2021.- Curso de Pedagogia- UNESC 


$\begin{array}{r}0,223 \\ +132,300 \\ \hline 133,023 \\ \hline 000,003 \\ 000,020 \\ 001,000 \\ 002,000 \\ 030,000 \\ 100,000 \\ \hline 133,023\end{array}$

Na sequência, desenvolveremos a tarefa 41 (ГОРБОВ et al., 2016), referente à subtração no sistema de base seis:

Tarefa 41: Faça a subtração: $(5,2)_{6}-(3,4)_{6}$.

Vale ressaltar que a essas alturas os estudantes já desenvolveram a compreensão do sistema numérico posicional e, consequentemente, da presença da vírgula tem apenas a função de indicar a separação entre as partes inteira e fracionária. Caso não existisse a vírgula, eles entenderiam que se tratava de $52_{6}-34_{6}$, cuja resolução é:

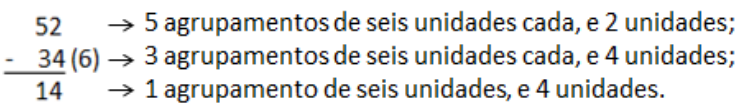

Para melhor ilustrar o processo de revolução, indicaremos passo a passo os procedimentos adotados. Iniciaremos pela subtração dos números da primeira ordem.

$$
\begin{array}{cc}
02_{6} \quad \text { A subtração não é possível, pois a unidade do } \\
-04_{6} \quad \text { minuendo é menor que a do subtraendo. }
\end{array}
$$

No entanto, é possível transformar 1 dos 5 agrupamentos da segunda ordem, em 6 unidades de primeira, que somam com as 2 unidades já contidas. Dessa forma, é possível subtrair 4, e restar 4:

$$
\begin{array}{r}
0^{1} 2_{6} \\
-04_{6} \\
\hline 04_{6}
\end{array}
$$

Como um dos 5 agrupamentos foi transformado em unidades, restam apenas 4 deles. Então, far-se-á a subtração de 4 grupos de 6, menos 3 grupos de 6:

$$
\begin{array}{r}
40_{6} \\
-30_{6} \\
\hline 10_{6}
\end{array}
$$

Portanto, tem-se como resultado um (1) grupo de seis unidades, e quatro unidades: Saberes Pedagógicos, Criciúma, v. 5, n² 2, maio/agosto 2021.- Curso de Pedagogia- UNESC 
O mesmo raciocínio/procedimento ocorre em relação ao número com vírgula. Nesse caso, dois e quatro são, as frações de ordem $\mathrm{m}^{-1}$. Logo, o resultado de " $(5,2)_{6}-(3,4) 6$ " é igual a $(1,4)_{6}$. Como confirmação de que a operação foi resolvida corretamente, cabe realizar a operação de adição do "resto" $(1,4)_{6}$ com o "subtraendo" $(3,4)_{6}$, com objetivo de que o resultado seja o "minuendo" $(5,2)_{6}$. Portanto, o número $(1,4)_{6}$ somado ao número $(3,4)_{6}$ precisa resultar em $(5,2)_{6}$. Ao somar a parte fracionária 4 do resto com a parte fracionária 4 do minuendo, se tem 1 agrupamento de 6 partes fracionárias que constituirá 1 unidade, e ainda restam 2 unidades fracionárias. Assim também, ao adicionar o 1 da parte inteira do resto com o 3 da parte inteira do subtraendo, acrescidos do novo agrupamento que se formou esgotado pelas casas fracionárias, obtêm-se 5 unidades.

Chegar a esse nível de apropriação conceitual das operações, no sexto ano, não é algo tão complexo, segundo Davídov (1988), pois há um processo miticuloso de organização de ensino, com tarefas particulares extremamente eleaboradas e articuladas entre si, em cada uma das seis ações de estudos, para que os estudantes entre em atividade de estudo. Toda essa articulação atende a tarefa estabelecida de que, a partir do quinto ano, os estudantes tenham condições de autonomia para eleaborar e propor as suas próprias tarefas.

Vale indicar alguns estudos, entre outros, que mostram tal processo relacionado a vários conceitos, os quais evidenciam as reais possibilidades para que os estudantes, no sexto ano escolar, transitam pelo estudo dos números fracionários posicionais sem manifestações de grandes dificuldades. Nesse sentido, Rosa (2012) estudou detalhadamente e com argumentos fundamentados teoricamente as mútiplas faces do conceito de número, adição e subtração e anunciativo de outros conexões conceituais. Madeira (2012) trata das idéia centrais dos conceitos de multiplicação. Crestani (2013) se debruçou sobre o estudo do conceito de divisão. Nessa mesma perspectva, Alves (2010) mostra com detalhe o processo de apropriação conceitual referente ao sistema conceitual de adição/subtração com inferência para a equação do primeiro grau. Por sua vez, Hobold (2014) investigou as manifestações do processo de apropriação do conceito de tabuada. Com mesmo objetivo, Mezzari (2014)

Saberes Pedagógicos, Criciúma, v. 5, n², maio/agosto 2021.- Curso de Pedagogia- UNESC 
pesquisou como ocorre o ensino de números e operações nas diversas bases, no segundo ano escolar. Mame (2014) centra sua investigação nas mútiplas interconexões dos conceitos geométricos, sem perder de vista a vinvulação com a álgebra e a aritmética. Freitas (2016) mostra o modo pelo qual os estudantes entram em atividade de estudo para apropriação do conceito de fração. Búrigo (2015) pesquisou as necessidades que emergem em cada tarefa particular que colocam os estudantes em movimento de pensamento conceitual peculiar aos números negativos.

Estes e outros estudos evidenciam o potencial do modo davidovyano de organização de ensino que colocam os estudantes em desenvolvimento da atividade de estudo para que transitem, no sexto ano, pelo sistema conceitual de frações posicionais com vírgula.

\section{OUTRAS CONSIDERAÇÕES}

No início dessa pesquisa, a intenção era estudar o modo pelo qual Davýdov e colaboradores propunham o ensino do conceito de números decimais. No entanto, não encontramos nos seus livros didáticos um tratamento exclusivo para esse conceito, como ocorre no ensino brasileiro. O que se apresentou foi a denominação "frações posicionais". Portanto, a apresentação dessas não ocorre na forma decimal, mas em outras bases, como o exemplo da tarefa 29. Isso se apresenta desde o segundo ano, em que os estudantes operam com números em diversos sistemas de contagem (agrupamento). Sendo assim, os números decimais não ganham o destaque como ocorreu em nosso processo de estudo escolar.

Dada essa ausência, o conceito matemático central da pesquisa passou a ser as frações posicionais. Estas se apresentam num contexto conceitual, em que a gênese e o desenvolvimento são as grandezas, no âmbito do processo de medição. Sua particularidade é que a unidade de medida não cabe vez inteira na grandeza a ser medida. Essa essência do conceito de fração aparece no livro do quarto ano, em que as tarefas sugerem a subdivisão da unidade, porém segue a mesma lógica adotada na contagem de quantidades inteiras. A diferença está que, na sua representação, as quantidades menores que um (1) são separadas por vírgula e ficam à direita do número representativo da primeira ordem. Nesse processo,

Saberes Pedagógicos, Criciúma, v. 5, n², maio/agosto 2021.- Curso de Pedagogia- UNESC 
como mostraram a análise das tarefas, há uma forte vinculação entre as significações aritméticas (quantidades numéricas), geométricas (áreas e segmentos de retas) e algébricas (sistema de dígitos com representação literal). A essência do conceito é traduzida no modelo, conforme Gorbov, et al. (2016):

Esse modelo - representativo da generalidade (parte inteira e fracionária) do sistema numérico e, também, as operações de adição e subtração de frações posicionais - é tratado no sexto ano escolar. A síntese, aqui realizada, revela que o problema de pesquisa e suas questões auxiliares estão, de certo modo, respondidas. No entanto, importa destacar que a presente pesquisa requer continuidade no âmbito das operações com os números decimais e relações entre os diversos sistemas numéricos, de acordo com o modo de organização davydoviano de ensino. Fica aberto o estudo, entre outros, de operações como: multiplicação, divisão, potenciação, radiciação, logaritmização, entre outras.

\section{REFERÊNCIAS:}

ALEKSANDROV, A. D. Visión General de la Matemática. In: ALEKSANDROV, A. D.; KOLMOGOROV, A. N.; LAURENTIEV, M. A. La matemática: su contenido, métodos y significado. Madrid: Alianza Editorial, p. 17-91, 1976.

ALVES, A. M. O método materialista histórico dialético: alguns apontamentos sobre a subjetividade. Revista de Psicologia da UNESP 9(1), 2010.

BÚRIGO, L. S. M. Necessidades emergentes na organização do ensino Davydoviano para o número negativo. Dissertação (Mestrado em Educação) - Universidade do Extremo Sul de Santa Catarina, Criciúma, 2015.

CARAÇA, B. J. Conceitos fundamentais da matemática. Lisboa: Livraria Sá da Costa Editora, 1984.

CRESTANI, S. Análise conceitual das proposições de Davydov e seus colaboradores para o ensino do conceito de divisão. 2013. 70 f. Monografia (Especialização em Educação Matemática) - Universidade do Extremo Sul Catarinense, Criciúma, 2013. 


\section{SABERES PEDAGÓGICOS}

Revista do Curso de Graduaçào de Pedagogia - Unesc

ISSN 2526.4559

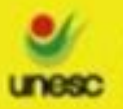

$\operatorname{tin}$

CHIZZOTTI, A. Pesquisa em ciências humanas e sociais. São Paulo: Cortez, 1991.

DAVÍDOV, V. V. La enseñanza escolar y el desarrollo psíquico: investigación teórica y experimental. Trad. Marta Shuare Moscú: Editorial Progreso, 1988.

DAVYDOV, V. V. Uma nova abordagem para a interpretação da estrutura e do conteúdo da atividade. In: CHAIKLIN, Seth; HEDEGAARD, M. (orgs.). Activity theory and social practive: cultural-historical approaches. Tradução de José Carlos Libâneo e Raquel Aparecida Marra da Madeira Freitas. Aarthus: Aarthus University Press, 1999.

DAVIDOV, V. V. Os problemas psicológicos do proceso de aprendizagem dos estudantes. In: PUENTES R. V., CARDOSO C. G. C., AMORIM P.A.P. (organizadores). Teoria da Atividade de Estudo: Contribuições de Elkonin, B. D., Davidov V. V., Repkin V. V. Curitiba: CRV, 2019 - Coedição: Uberlandia, MG: EDUFU, p. 171-173, 2019.

DAVIDOV, V. V.; MÁRKOVA, A. K. O conceito de Atividade de Estudo dos estudantes das séries iniciais do nível fundamental. In: PUENTES R. V., CARDOSO C. G. C., AMORIM P.A.P. (organizadores). Teoria da Atividade de Estudo: Contribuições de Elkonin, B. D., Davidov V. V., Repkin V. V. Curitiba: CRV, 2019 - Coedição: Uberlândia, MG: EDUFU, p. 171-173, 2019.

EVES, Howard. Introdução à história da matemática. Campinas: Unicamp, 2004.

FREITAS, R. A. M. M. Conhecimento disciplinar, conhecimento pedagógico-didático e qualidade do ensino aprendizagem na educação básica. In: VIEIRA, C. M. N.; BIGARELLA, N.; FERREIRA, V. A. (organizadores). Politicas e práticas educacionais em diferentes contextos da educação básica. Curitiba: CRV, 2016.

FREITAS, D. O Movimento do Pensamento Expresso nas Tarefas Particulares Proposta por Davydov e Colaboradores para a Apropriação do Sistema Conceitual de Fração. 2016. 167 fls. Dissertação (Mestrado em Educação) Universidade do Extremo Sul Catarinense, Criciúma/SC.

HOBOLD, E. S. F. Proposições para o Ensino da tabuada com base nas Lógicas Formal e Dialética. 2014. 199 f. Dissertação (Mestrado em Educação)-Universidade do Sul de Santa Catarina, UNISUL, Tubarão, 2014.

LIBÂNEO, J. C. \& FREITAS, R. A. M. M. Vasily Vasilyevich Davydov: a escola e a formação do pensamento teórico-científico. In: LONGAREZI, A. M. \& PUENTES, R. V. (Org.). Ensino Desenvolvimental: vida, pensamento e obra dos principais representantes russos. Uberlândia, MG: EDUFU, 2013, p. 27-41.

Saberes Pedagógicos, Criciúma, v. 5, n², maio/agosto 2021.- Curso de Pedagogia- UNESC 
MADEIRA, S. C. "Prática": Uma leitura Histórico-Crítica e proposições davydovianas para o conceito de multiplicação. 2012. 165 f. Dissertação (Mestrado em Educação) - Universidade do Extremo Sul Catarinense, Criciúma, 2012.

MAME, O. A. C. Os conceitos geométricos nos dois anos iniciais do Ensino Fundamental na proposição de Davýdov. 2015. 160 f. Dissertação (Mestrado em Educação) Universidade do Extremo Sul Catarinense, Criciúma, 2014.

ROSA, J. E. Proposições de Davydov para o ensino de Matemática no primeiro ano escolar: inter-relações dos sistemas de sistema de significações numéricas. Tese de Doutorado em Educação. Universidade Federal do Paraná, Curitiba, 2014.

ROSA, J. E.; DAMAZIO, A.; SILVEIRA, G. M. O Sistema de numeração nas Tarefas Propostas por Davýdov e seus Colaboradores para o Ensino de Matemática. Bolema: Boletim de Educação Matemática, [s.1.], v. 28, n. 50, p.1135-1154, dez. 2014. Fap UNIFESP (SciELO). http://dx.doi.org/10.1590/1980-4415v28n50a07.

SOUZA, M. B. O ensino do conceito de número: objetivação nas proposições davydovianas e formalista moderna. Dissertação de Mestrado em Educação, Universidade do Extremo Sul Catarinense, Criciúma, 2013.

VIGOSTSKI, L. S. A construção do pensamento e da linguagem. São Paulo: Martins Fontes, 2001.

VYGOTSKI, L. S. Obras Escogidas. Tomo III. Madrid: Visor, 1996.

VIGOSTSKI, L. S. A construção do pensamento e da linguagem. São Paulo: Martins Fontes, 2001.

ГОРБОВ, С. Ф. et al. Математнка. Учебное пособне для 6 класса. Москва: Авторский Клуб, 2016.

Financiamento:

Programa Institucional de Bolsas de Iniciação Científica da Unesc; CNPQ: Chamada MCTIC/CNPq No 28/2018 - Universal. 